Dokuz Eylül Üniversitesi-Mühendislik Fakültesi

Fen ve Mühendislik Dergisi

Cilt 19, Sayı 57, Eylül 2017
Dokuz Eylul University-Faculty of Engineering Journal of Science and Engineering Volume 19, Issue 57, September 2017

DOI: $10.21205 /$ deufmd.2017195771

\title{
Sinter Makinesinin Örüntü Tanıma Tabanlı Otomatik Hız Kontrolü
}

\author{
Ahmet BEŞKARDES ${ }^{*}{ }^{1}$, Merve ERKINAY ÖZDEMIR ${ }^{2}$ \\ ${ }^{1}$ İskenderun Demir ve Çelik A.Ş. (İSDEMİR), Elektronik Otomasyon Müdürlüğü, Hatay \\ 2İskenderun Teknik Üniversitesi, Elektrik Elektronik Fakültesi, Elektrik Elektronik \\ Mühendisliği Bölümü, Hatay
}

(Alınış / Received: 28.11.2016, Kabul / Accepted: 31.05.2017, Online Yayınlanma / Published Online: 20.09.2017)

Anahtar Kelimeler Özet: Sinter tesisleri, yüksek fırın kullanılarak demir çelik üretimi Sinter, Isıl Kontrol, yapılan entegre demir çelik fabrikalarının önemli bir parçasıdır. BRP, BTP, Sinter tesislerinin ana bölümlerinden biri olan sinter makinesinde toz cevherin sinterleşmesi sağlanarak yüksek firında kullanılmaya elverişli hale getirilir. Bu çalışmada, sinter makinesinin verimini artırmak amacıyla, makine yönetiminin operatörlerden alınıp otomatik yapılması için bir örüntü tanıma sistemi tasarlanmıştır. Dogrusal Ayırma Sinıflandırıcısı, Yapay Sinir Ağı, Destek Vektör Tasarlanan bu sistemde sınıflandırıcı olarak doğrusal ayırma sinıflandırıcısı, destek vektör makineleri ve yapay sinir ağı Makineleri kullanılmıştır. Bu sınıflandırıcılar 4212 adetlik bağımsız veri kümesi üzerinde test edilerek birbiri ile karșılaștırılmıștır.

\section{Automatically Sinter Machine Speed Control With Pattern Recognition Based System}

\begin{tabular}{l}
\hline Keywords \\
Sinter, \\
Thermal Control, \\
BRP, \\
BTP, \\
Pattern \\
Recognition, \\
Linear \\
Discriminant \\
Classifier, \\
Artificial Neural \\
Network, \\
Support Vector \\
Machine
\end{tabular}

\begin{abstract}
Sinter plant is one of the important unit of the integrated plants, which made iron and steel production via blast furnace. In the sinter machine, which is the main part of the sinter plant fine ore has been provided sintering and rendered suitable for using in the blast furnace. In this study, aimed to increasing sinter machine production a pattern recognition system has been developed for automatic control instead of operator's control. Linear discriminant classifier, support vector machines and artificial neural network is used in designed system. These classifiers were compared to each individual data set by testing over 4212 units.
\end{abstract}




\section{Giriş}

Sıvı ham demirin yüksek firınla elde edildiği entegre demir çelik tesislerinde sinter tesislerinin önemli bir yeri vardır. Yüksek fırınlara şarj edilen demirli malzemenin önemli bir kısmını sinterlenmiş malzeme oluşturur. $\mathrm{Bu}$ sinterlenmiș malzeme (sinter), demir çelik fabrikasında doğrudan kullanılamayacak toz cevher, kok tozu, baca tozu, tufal gibi malzemelerin değerlendirilmesi ile elde edilir. Yüksek firınlara şarj edilen cevher, pelet ve sinter içinde sinterin pelete göre ucuz olması ve sinterin atık malzemelerden üretilmesi demir çelik fabrikasının üretim maliyetini düșürmesine doğrudan etki eder.

Sinterleme, makineye serilen malzemenin üstten tutuşturulup alttan hava çekilmesi ve kok tozu adı verilen yakıtın sağladığı ısı ile cevherin ergitilmesi işlemidir. $\mathrm{Bu}$ sinterleme işleminin makinenin sonuna yakın bir yerde tamamlanması çok önemlidir. Sinter makinesinin verimi sinterleme ișleminin tam ve doğru zamanlama ile yapılmasına bağlıdır.

$\mathrm{Bu}$ çalıșmada, sinterleme işleminin en verimli şekilde yapılması için emiş kamaraları sıcaklıkları, harman yüksekliği ve emiş basınçları parametrelerini değerlendirip makine hızının hangi yönde yükseltilip düşürülmesi gerektiğini öneren bir sistem geliştirilmiştir.

Bu çalıșmanın amacl, sinter makinesinin hızını bilgisayar tabanlı ayarlayarak sinter fabrikasının üretim miktarını artırmak ve sinter makinesi hızının kontrolünü insandan bağımsız hale getirmektir. $\mathrm{Bu}$ çalışma ile sinter makinesinin hız ayarının operatörden bağımsız çalışması ve doğru zamanda, doğru oranda yapılacak hiz değişimleriyle makine veriminin, dolayısıyla da üretiminin artırılması sağlanacaktır.

Sinter makinesini optimum hızda çalıştırmak için ısıl kontrol üzerinde durulmuştur. Isıl kontrol, sinter makinesi üzerindeki malzemenin sıcaklık artıșının en yüksek olduğu Sıcaklık Yükselme Noktası (Burning Rising Point - BRP) ve malzeme sıcaklığının en yüksek değerine ulaştığı Sıcaklık Kararlılık Noktası (Burning Through Point - BTP) değerlerine bakarak makine hızını tayin etme olarak özetlenebilir.

Xiang ve arkadaşları, BTP ve bunker kontrolünü beraber ele aldıkları çalışmada, BTP kontrolünü ateşleme koşulları, yataktaki malzeme yüksekliği, ilave edilen su miktarı, emiş fanlarının açıklık oranı gibi parametrelerin yerel olarak kontrol edildiğini kabul edip kamara sıcaklıklarını kullanarak yapmışlardır. Son altı kamara sıcaklığı bilgilerini ikinci derece bir polinoma uygulayarak sıcaklık değişimini tespit edip BTP noktasını hesaplamışlar ve bu nokta ile referans BTP noktasını bir bulanık denetleyiciye girip Gaussian tipi bir üyelik fonksiyonuyla sistemi kararlı çalıştıracak makine hızı bilgisini üretmişlerdir[1]. İlerleyen yıllarda ısıl kontrol konusunda daha detaylı ve karma çalışmalar yapılmıştır. Wu ve arkadaşları, bulanık denetleyici ve yapay sinir ağlarını kullandıkları çalışmalarında kamara sıcaklıklarını ikinci derece bir polinoma uygulayarak, en yüksek sıcaklık değerine karşılık gelen BRP ve BTP konum noktalarını bulmușlardır. $\mathrm{Bu}$ noktaları gri tahmin modeline uygulayarak bir sonraki BTP noktasını hesaplamışlardır. Daha sonra hesaplanan ve istenen BTP noktaları türevsel bulanık denetleyici ve öngörülü bulanık denetleyicilere uygulayarak makine hızı bilgisi üretmiş̧lerdir. Çalışmaları sonucunda 16,4-17,6 aralığında tutulabilen BTP konum noktası değeri 16,8-17,2 aralığına çekilerek iyi bir 
kararlılık yakalanmıştır[2]. Song ve arkadaşları, yaptığı çalışmada kamara sıcaklıklarından yukarıdaki yöntemlerle elde ettiği BTP noktasını Bayes En Küçük Kareler Destek Vektör Makineleri, Gri Model ve Yapay Sinir Ağlarında kullanmışlardır. Özellikle büyük veri setleri ile çalıșıldığında Bayes En Küçük Kareler Destek Vektör Makineleri yönteminin diğerlerine göre daha yüksek doğruluklara ulaştırdığı ve işlem süresinin daha kısa olduğu görülmüştür[3]. Wang ve arkadaşları yapay sinir ağı ve çoklu doğrusal regresyon ile tasarladıkları yapıda sıcaklık, basınç, nem gibi proses parametreleri ve hammadde dozaj bilgilerinden oluşan girdi değerlerinden BTP sıcaklık ve konum noktalarını tahmin ederek bu noktaların istedikleri referans değere olan uzaklığına göre kontrol parametrelerini değiștiren bir kapalı devre kontrol sistemi kurmuşlar ve bu sayede BTP kararlılığını istedikleri seviyede tutmuşlardır[4].

$\mathrm{Bu}$ çalışmada sinter makinesine daha erken müdahale edebilmek için BTP noktası yerine BRP noktası kullanılmıştır. Literatürde güncel sıcaklıkların bir kabule dayanan referans değere göre karşılaştırılması yapılırken [1,2], bu çalışmada farklı olarak güncel ve referans olarak hesap edilen BRP noktaları arasındaki fark değerlendirmeye alınmıştır. Güncel BRP noktası her 5 dakikada bir sıcaklık verilerinden sürekli olarak hesaplanmaktadır. Referans BRP noktası ise sinter makinesinin en verimli kullanıldığı zaman diliminde toplanan verilerden hesaplanmaktadır. Güncel ve referans BRP noktaları arasındaki farkla beraber emiş basınçları, harman seviyesi ve mevcut hız verileri kullanılarak sınıflandırıcılar eğitilmiş ve eğitim verisi içermeyen bağımsız test verileri üzerinden sonuçları karşılaștırılmıștır.

\section{Materyal ve Metot}

Sinterleme, yüksek firınlarda kullanılamayacak olan boyutu yaklaşık olarak $10 \mathrm{~mm}$. nin altında olan toz cevherlerinin, kok tozu yardımıyla kısmi ergitilmeye uğratılarak boyutunun büyütülmesi işlemidir. Sinterleme işlemi ile toz halindeki cevher ve kokun kullanılması, cevher içindeki zararlı içeriklerin bertaraf edilmesi ve yüksek fırına daha düşük maliyetli hammadde sağlanması hedeflenir.

Sinter harmanı için toz cevher, kok tozu, kireçtaşı, dünit, sinter tozu ve yüksek firın tozu gibi malzemeler kullanılır. Bu malzemeler Şekil 1'de gösterildiği gibi dozajlama ünitesindeki silolara doldurulur. $\mathrm{Bu}$ malzemeler kantarlar aracılığıyla tartılır, oranlanır ve makinede tüketilen miktara göre makineye beslenir. Dozajlama ünitesinde oranları ve miktarları belirlenen bu malzemeler karıştırıcılarda karıştırılıp nemlendirilerek sinter makinesinin başında bulunan malzeme bunkerine aktarılır. Malzeme bunkerinin altında bulunan tambur besleyici ile malzemenin istenen yükseklikte ve düzgün bir şekilde sinter paletine beslenmesi sağlanır. Ateşleme ünitesi ile malzemenin üst kısmından yanma işlemi başlatılır. Kok tozunun yanması sinter paletinin altında bulunan emiş kamaralarından çekilen hava ile hızlandırılır. Makinenin sonuna gelindiğinde malzeme içindeki kok biter ve bu arada sinterleşme sağlanır.

Sinter makinesindeki sıcaklı bilgisi, makinenin altında bulunan emiş kamaralarındaki çıkış gazı sıcaklıklarından ölçülür. BRP ve BTP noktaları bu sıcaklık değerlerine göre hesaplanır. BRP noktası, malzeme içindeki nemin tamamen bittiği anda sıcaklığın sıçrama yaptığı yerdir. BTP noktası ise kokun yanarak tamamen bittiği ve malzemenin sinterleştiği yerdir. Sinterleşme işlemi bittikten sonra malzeme kırıcılarda kırılır ve elenerek 
istenen boyutta olanları yüksek firınlara gönderilir. Diğerleri ise geri dönüş tozu olarak tekrar sinter makinesine beslenir.

Sinterleşme sırasında malzemede nem kaybı, redüklenme, ergime ve katılaşma gibi birçok fiziksel ve kimyasal olaylar meydana gelir. Sinter prosesinin kararlılığı, cevher tipi, kok tozu oranı, malzemenin düzgün dağıtılması, firın sıcaklığı, emiş basınçları gibi birçok faktörden etkilenir. Bu parametrelerden bazılarını ölçümlemeye imkân yoktur. Ölçülebilen parametrelerin ölçüm zamanları arasında da büyük farklar vardır. Ayrica bu parametreler arasındaki ilișki doğrusal değildir[5].

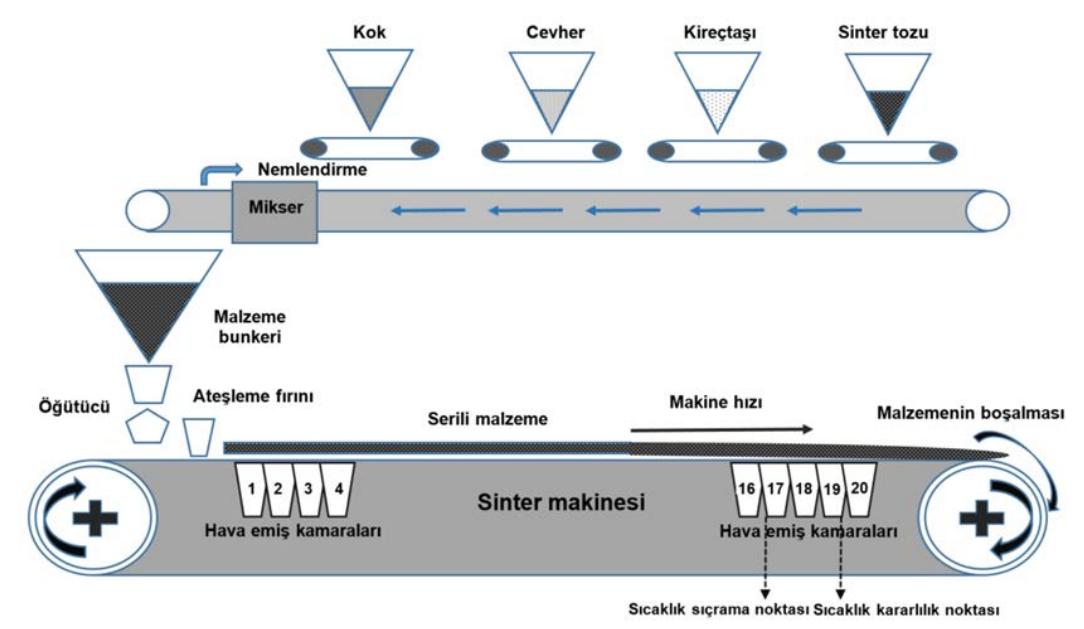

Şekil 1. Sinter üretimi

İsdemir sinter tesislerinin uzman mühendis ve operatörlerine göre üretimin en verimli yapıldığı durumda, sinter paletine serilen malzemenin yüksekliği yaklaşı $600 \mathrm{~mm}$, emiş vakumu (eksi basınç) $15 \mathrm{kPa}$, makine hızı ise yaklaşık $3.5 \mathrm{~m} / \mathrm{dk}$ büyüklügündedir. Böyle bir durumda BRP konumu 17.5 (17 ile 18 nolu kamaranın ortası) olur. BTP konumu ise 19 (19 nolu kamaranın başı) olur. BRP ve BTP noktalarının ideal noktalardan geride olması sinterleşme sürecinin tamamlanmadan malzemenin makineyi terk ettiğini gösterir. Aksine ileride olması ise sinterleşmenin çok önceden bittiği ve makinenin soğutma amaçlı kullanıldı̆̆ını gösterir. Her iki durumda da sinter kalitesi ve verimi kötü etkilenecektir.

\section{1. Örüntü Tanıma Sistemi}

Örüntü, düzenli ya da benzer şekilde tekrar edebilen ölçümlenebilir ya da gözlemlenebilir örnekler kümesidir. El yazısı, ses sinyali, parmak izi, bir metindeki karakterler örüntüye bir örnek olarak verilebilir. Örüntü tanıma ise, aralarında ilişki kurulabilen bu örnekleri belirli özelliklere göre sınıflandırmaktır [6]. Örüntü tanıma uygulamalarının amacl, makinenin gördüğü örüntülerin özniteliklerini kullanarak daha önceden eğitildiği ya da öğrendiğine göre bu örüntülerin sınıflandırmasını yapmaktır [7]. Örüntü tanıma, makine öğrenmesinin önemli bir basamağıdır. $\mathrm{Bu}$ görevi bilgisayar yazilımları ile makinelere yaptırma her geçen yıl büyüyerek devam etmektedir [8]. Örüntü tanıma teknikleri istatistiksel ve yapısal teknikler, şablon eşleştirme, yapay sinir ağı, bulanık mantık ve karma yaklaşımlar olarak alt kısımlara ayrılabilir[9,10]. Örüntü tanıma metodolojisi genel olarak öznitelik çıkarma ve sınıflandırma olmak üzere 
ikiye ayrılır. Öznitelik çıkarma işlemi prosesin kısa ama anlamlı bir sunumunu elde etmektir. Elde edilen bu karakteristik bilgiler bir sonraki aşamada farklı karar bölgeleri içine alınarak sinıflandirılır[11].

$\mathrm{Bu}$ çalıșmada tasarlanan örüntü tanıma sisteminde ilk olarak sinter makinesi ile ilgili tüm üretim verileri toplanmıştır. $\mathrm{Bu}$ veriler, PLC (programmable logic controller) ünitelerinden anlık olarak elde edilen sinyallerin veri tabanına belirli aralıklarla kaydedilmesi ile oluşturulmuştur. Daha sonra işletme tecrübeleri ve temel sinter üretim prensipleri ışığında bu veriler değerlendirilerek tasarlanan sistemin giriş ve çlkış parametreleri belirlenmiştir. Daha sonra üç farklı sınıflandırıcı eğitilip test edilerek genel performansı incelenmiş, daha sonra da eğitilen sınıflandırıcılar bağımsız test verileri kullanılarak birbiri ile kıyaslanmıştır.

\subsection{Veri setinin elde edilmesi}

Sinter Seviye 2 otomasyon sistemi ile sinter makinesi üretim verileri Microsoft.NET platformunda C\# dilinde Tablo 1. Veri setini olușturan parametreler.

\begin{tabular}{|c|c|c|}
\hline Parametre Adı & Açıklama & Birimi \\
\hline Sicaklıklar & Emiş kamara sıcaklık değerleridir. & ${ }^{\circ} \mathrm{C}$ \\
\hline BRP Konum Noktası & $\begin{array}{l}\text { Sicaklık değerlerinden hesaplanan ani } \\
\text { sıcaklık yükselişinin yaşandığı konum } \\
\text { bilgisidir. }\end{array}$ & $\begin{array}{l}\text { Kamara } \\
\text { konumu }\end{array}$ \\
\hline BRP Sicaklık Noktası & $\begin{array}{l}\text { Sıcaklık değerlerinden hesaplanan ani } \\
\text { yükselişin olduğu sıcaklık bilgisidir. }\end{array}$ & ${ }^{\circ} \mathrm{C}$ \\
\hline Harman Seviyesi & $\begin{array}{c}\text { Sinter makinesi üzerine serilen malzeme } \\
\text { yüksekliğidir. }\end{array}$ & $\mathrm{mm}$ \\
\hline Basınç & $\begin{array}{l}\text { Yanma işleminin alt bölgelere kadar } \\
\text { ulașması için olușturulan fark basıncıdır. }\end{array}$ & $\mathrm{kPa}$ \\
\hline Makine Hızı & Sinter makinesinin palet ilerleme hızıdır. & $\mathrm{m} / \mathrm{dk}$ \\
\hline Elek Sayısı & $\begin{array}{l}\text { Makinenin sonunda eleme ișleminin } \\
\text { yapıldığı elek adedidir. }\end{array}$ & adet \\
\hline Sıcaklık Eğilimi & $\begin{array}{c}\text { BRP sıcaklığının düşüş ya da yükseliş eğilimi } \\
\text { bilgisidir. }\end{array}$ & ${ }^{\circ} \mathrm{C}$ \\
\hline BRP Kayma Toleransı & $\begin{array}{l}\text { BRP konum noktasının referans noktadan ne } \\
\text { kadar geride ya da ileride olması durumunda } \\
\text { işlem yaplacağı bilgisidir. }\end{array}$ & - \\
\hline Hız Müdahale Yönü & $\begin{array}{c}\text { Makine hızına yapılan müdahaleyi gösteren } \\
\text { çıkıș parametresidir. }\end{array}$ & - \\
\hline
\end{tabular}

yazılan bir uygulama ile sürekli kayıt altına alınmaktadır. $\mathrm{Bu}$ çalışmada kullanılan veriler 1 Ağustos 2014 ile 15 Ocak 2015 tarihleri arasındaki üretim verileridir. Bu tarih aralığındaki veriler sinter makinesi Seviye 2 sistemi veri tabanından veri tabanı sorgusu ( Structured Query Language - SQL) ile çekilmiştir. Önce sıcaklık bilgileri, sıcaklık bilgilerinden Beşkardeş ve arkadaşlarının önerdiği yönteme [12] göre hesaplanan BRP (Burn rising point sıcaklık sıçrama noktası) değerleri, harman yüksekliği, emiş basınçları, mevcut hız bilgisi, elek çalışma durumları verileri elde edilmiş daha sonra aşağıdaki șartlara göre bu veriler filtrelenmiș ve Tablo 1'de gösterilen veri seti oluşturulmuştur.

- Harman seviyesi 500 - 600 mm aralığında olmalıdır.

- Eleklerin ikisi de çalışır durumda olmalıdir.

- Ortalama vakum $16,5 \mathrm{kPa}$ değerinden küçük olmalıdır.

- Makine yeni çalışmış durumda olmamalıdır. 
Çalışmada kullanılacak veri seti 14040 kayıttan oluşmaktadır. Verilerin doğruluğunu sağlamak ve çalışacak yöntemleri hızlandırmak için veri setinde aşağıdaki gibi ön işlemler yapılmıştır:

- Kayıtlar zamana göre sıralanmış ve aralarında öneri süresinden (5 dakika) daha büyük bir fark olanlar değerlendirme dişı tutulmuştur.

- Sinter makinesi işletme şartlarına göre değişiklik arz eden BRP konum noktasındaki kayma toleransı verilere eklenmiștir.

- Sicaklıkların yükselme ya da düşme eğiliminde olmasının sonuca doğrudan etkisi olduğu bilindiğinden, toplanan verilerden bu parametre elde edilerek ayrı bir parametre olarak kullanılmıştır. Sicaklıklar yükselme eğiliminde ise bu parametrenin değeri 1, düşme eğiliminde ise -1 kabul edilmiştir.

Tablo 1'de görülen sıcaklık verileri, giriş parametresi olarak kullanılmamış, BRP noktalarını hesaplamak için veri setine dâhil edilmiștir. BRP konum noktası ve BRP sıcaklık noktası sıcaklık verilerinden hesaplanmıştır. Harman seviyesi, malzemenin sinter paletine serildiği yerde ölçülen malzeme yüksekliği bilgisidir. Basınç bilgisi yanma işleminin alt bölgelere kadar ulaşması için sinter ana egzoster fanı tarafindan oluşturulan fark basınç büyüklüğüdür. Makine hızı, sinter paletinin bir dakikada kat ettiği mesafeyi gösterir. Elek sayısı, veri setinde filtreleme amacıyla kullanılmıș, buna göre bir işletme problemi olan tek elekte çalışma durumu olduğunda toplanan veriler değerlendirmeye alınmamıștır. Sıcaklık eğilimi bilgisi ardışık BRP sıcaklık değerlerinden hesaplanan ve sıcaklık eğiliminin yönünü gösteren bir parametredir. Sicaklık yükseliyorsa 1, düşüyorsa -1 değerini alır. BRP kayma toleransı ise işletme mühendisinin atadığı sınır değerlerine göre BRP konum noktasına göre hesaplanmıștır. BRP kayma toleransı güncel BRP konum noktasının referans BRP konum noktasından ne kadar farklı olması durumunda hıza müdahale edilmesi gerektiğini ifade eder. Son olarak, çıkış parametresi olan hıza müdahale yönü, makine hızına ne yönde müdahale edileceğini gösterir. $\mathrm{Hız}$ yükselt, hız düşür, hızı aynı bırak şeklinde üç farklı komut bilgisidir.

Tablo 2' de ise veri setinin oluşturulduğu zaman diliminde parametrelere ait istatistik bilgileri verilmiștir. Bu tabloda, kullanılan parametreler hakkında daha iyi bir fikir yürütülebilmesi için veri kümesinin oluşturulduğu 01.08.2014 ile 15.01.2015 tarihleri arasinda toplanan verilerin minimum, maksimum, ortalama ve standart sapma değerleri gösterilmiştir.

Tablo 2. Parametrelere ait istatistik bilgileri.

\begin{tabular}{ccccc}
\hline & Min. & Mak. & Ort. & S. Sapma \\
\hline BRP Güncel Konum (kk) & 16,01 & 18,29 & 17,18 & 0,56 \\
BRP Güncel Sicaklık $\left({ }^{\circ} \mathrm{C}\right)$ & 131,01 & 379,69 & 244,15 & 36,88 \\
BRP Referans Konum $(\mathrm{kk})$ & 16,01 & 17,87 & 17,38 & 0,22 \\
BRP Referans Sicaklı $\left({ }^{\circ} \mathrm{C}\right)$ & 182,62 & 299,87 & 262,16 & 13,60 \\
Harman Seviyesi $(\mathrm{mm})$ & 502,83 & 599,94 & 568,96 & 13,54 \\
Basınç $(\mathrm{kPa})$ & $-16,49$ & $-2,67$ & $-15,41$ & 0,72 \\
Makine Hızı (m/dk) & 2,20 & 4,30 & 3,39 & 0,21 \\
Sicaklık Eğilimi ( $\left.{ }^{\circ} \mathrm{C}\right)$ & $-1,00$ & 1,00 & 0,10 & 1,00 \\
Hız Yükseltme İçin BRP Kayma & 0,10 & 0,50 & 0,22 & 0,11 \\
Toleransı (kk) & & & & \\
\hline
\end{tabular}




\subsection{Sinıflandırma}

Bu çalışmada sınıflandırma için doğrusal ayırma sinıflandırıcısı, yapay sinir ağı ve destek vektör makineleri kullanılmıştır. Sinıflandırma işlemleri Matlab platformunda yazılan kod blokları ile gerçekleştirilmiştir.

Doğrusal ayırma sınıflandırıcısı: İstatistik ve makine öğrenmesi alanlarında yaygın olarak kullanılan sınıflandırma yöntemlerinden biridir. Doğrusal ayırma sınıflandırıcısı, iki veya daha fazla sınıfa ait olan örnekleri doğrusal olarak ayırmak için, özniteliklerin doğrusal kombinasyonunu bulmaya çalışır. Bu yöntemde önce ayırt edici fonksiyonlar belirlenir. Daha sonra bu fonksiyonlar aracılığıyla, gruplar içinde en baskın olan ayırt edici değişkenler belirlenir ve bu örneğin hangi gruba ait olduğuna karar verilir [13].

Doğrusal sınıflandırma, bir sınıfın diğer sınıflardan ayrılması işleminin doğrusal olarak yapılmasıdır. Sonucun ne olduğunun değil, hangi sınıf içinde olduğunun önemi vardır. Böyle bir sınıflandırmada sınırlarla ayrılmış sınıf bölgelerindeki örneklerin nasıl dağıldı önemli değildir, önemli olan sinıflar arasındaki sınırların nasıl kestirildiğidir. $\mathrm{Bu}$ kestirim ne kadar iyi yapılırsa sınıflandırma başarısının o kadar yüksek olduğu düşünülür [14].

Doğrusal ayırma sinıflandırıcısı kullanmada amaç yapılan işlemin daha basit olması ve daha düşük sistem gereksinimlerine ihtiyaç duymasıdır. Doğrusal modelin anlaşılması kolaydır: Modelin çıktısı, Denklem 1'de görüldüğü gibi $\mathrm{x}_{\mathrm{j}}$ girdilerinin ağırlıklı toplamıdır. $\mathrm{w}_{\mathrm{j}}$ ağırlığının büyüklüğü, $\mathrm{x}_{j}$ girdisinin önemini ve işaretini belirtir.

$$
g_{i}\left(x \mid w_{i}, w_{i 0}\right)=w_{i}^{T} x+w_{i 0}=\sum_{j=1}^{d} w_{i j} x_{j}+w_{i 0}
$$

Yapay sinir ağı: Yapay sinir ağları (YSA) insan beynindeki sinir hücrelerinin katmanlı ve bağlantılı yapısından esinlenerek geliştirilmiştir. Her biri kendi belleğine sahip ve ağırlıklı bağlantılar aracılığıyla birbirine bağlanmış, paralel çalışan bilgi işleme yapılarıdır [15]. Kendi kendine öğrenme ve organize etme, hata toleransina sahip olma gibi özellikleriyle örüntü tanıma uygulamalarında çokça tercih edilir[10].

Bir yapay sinir ağı birbirleriyle bağlantılı çok sayıda sinirden (düğümden) oluşur. Her bir sinirin Şekil 2' de gösterildiği gibi öğeleri vardır. $\mathrm{Bu}$ öğeler girişler, ağırlıklar, toplama fonksiyonu, aktivasyon fonksiyonu ve çıktı olarak isimlendirilir.

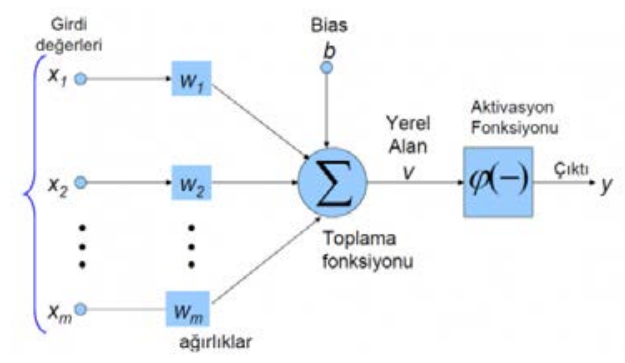

Şekil 2. Yapay sinir ağı genel yapısı

Girişler $\left(\mathrm{x}_{1}, \mathrm{x}_{2} \ldots, \mathrm{x}_{\mathrm{m}}\right)$, kendinden önceki sinirden ya da diş dünyadan sinire gelen bilgilerdir. Ağırlıklar $\left(\mathrm{w}_{1}, \mathrm{w}_{2} \ldots, \mathrm{w}_{\mathrm{m}}\right)$ girişlerin sinir üzerindeki etkisini belirleyen katsayılardır. Bir ağırlı̆̆ın değerinin büyük olması o girişin sonuç üzerindeki etkisinin büyüklüğünü gösterir. Toplama fonksiyonu $\mathrm{v}_{\mathrm{m}}$ sinirde her bir ağırlıkla girişin çarpımının toplamlarını eşik değeri $\theta_{m}$ ile toplayarak aktivasyon fonksiyonuna gönderir. Toplama işleminin sonucu aktivasyon fonksiyonundan geçirildikten sonra çıkışa gönderilir. Yapay sinir hücresi, aktivasyon fonksiyonunun eşik seviyesinin altında çıkış üretmez, üstünde ise üretir. Hücrenin verdiği sonuç belli bir katsayı ya da ölçekle çarpılıp ya da bazı sınırlara göre değerlendirilerek daha anlamlı bir hale getirilebilir. Çılktı ise yapılan işlemin 
sonunda üretilen dışarıya ya da başka bir sinire gönderildiği yerdir.

Yapay sinir ağları, öğrenme mekanizmasına göre "Danışmanlı" ve "Danışmansız" olmak üzere iki gruba ayrılmıștır. Çalışmada hedef çıkış değerleri varsa öğrenme mekanizması danıșmanlı öğrenme, yoksa danıșmansız öğrenme olarak adlandırılır [7].

Yapay sinir ağları mimari yapılarına göre ileri beslemeli ağlar (Feed Forward) ve geri beslemeli ağlar (Feed Back) olmak üzere ikiye ayrlabilir. Geri beslemeli ağlarda bir sinirin çıkışı kendinden önceki katmanlarda bulunan sinirlerin girişine iletilmektedir [16]. Bu tip sinir ağlarının hafızaları dinamiktir ve çıkıș hem anlık hem de önceki girişleri yansitır. Bundan dolayı bu tip ağlar danışmansız öğrenme yapılan uygulamalar için daha uygundur. İleri beslemeli bir ağda ise, her katmandaki sinirlerin çıkışları ilgili ağırlıklarla çarpılarak bir sonraki sinire giriş değeri olarak verilir. $\mathrm{Bu}$ işlem çıkış katmanına varıncaya kadar devam eder. Bu ağlar çok katmanlı ileri beslemeli ağlar olarak adlandirılır [15].

Destek vektör makineleri: Destek vektör makineleri (DVM), Vapnik tarafından geliştirilen ve istatistiksel öğrenme teorisine dayanan bir yöntemdir. $\mathrm{Bu}$ yöntemde giriş uzayı, özellik uzayı denen ve içinde sınıflandırıcının genelleme kabiliyetini artırmak için en uygun düzlemlerin belirlendiği çok boyutlu bir iç çarpım uzayı üzerinde haritalandırılır. En uygun düzlemler, optimizasyon teorisi ve bununla ilişkili istatistiksel öğrenme teorisi kullanarak bulunur [17].

Destek vektör makineleri, çok sayıda bağımsız değişkenle çalışabilme, çok az giriş ile öğrenebilme, doğrusal olarak ayrılabilen ya da ayrilamayan verilere uygulanıp yüksek doğrulukta sonuçlar verme bakımından avantajlıdır.

Doğrusal olarak ayrılabilen bir destek vektör makinesinde $\mathrm{N}$ adet gözlemden oluşan ve her biri bir veri çiftinden oluşan veri vektörü n-boyutlu uzayda $n$ $\mathrm{X}_{\mathrm{i}} \in \mathrm{R}$ ve $\mathrm{i}=1,2, \ldots, \mathrm{N}$ olmak üzere, veri vektörlerine karşılık gelen sınıf etiketi $\mathrm{y}_{\mathrm{i}}$ $\epsilon\{+1,-1\}$ olsun. Bu durumda $\mathrm{y}_{\mathrm{i}}=+1$ ise $\mathrm{x}_{\mathrm{i}}$ I. sınıfa, $y_{i}=-1$ ise $x_{i}$ II. sınıfa dâhil edilir. $\mathrm{Bu}$ veri çiftleri eğitim setini oluşturmaktadır. Doğrusal olarak birbirlerinden ayrılabilen veriler için, bu verileri birbirinden ayıran bir $\mathrm{f}$ ( $\mathrm{x}$ ) aşırı düzlemi tanımlanabilir. Bu aşırı düzlemi tanımlamak için, xi pozitif sınıfa ait ise $\mathrm{f}$ $(x) \geq 0$ ve $x_{i}$ negatif sinifa ait ise $f(x)<0$ şartı uygulanır [18].

$$
\begin{aligned}
& f(x)=\mathrm{w}^{T} \cdot x+b=\sum_{j=1}^{n} w_{j} \cdot x_{j}+b \\
& y_{i} f\left(x_{i}\right)=y_{i}\left(\mathrm{w}^{T} \cdot x+b\right) \geq 0 \quad i=1,2, \ldots N
\end{aligned}
$$

Denklem 2 ve Denklem 3'te, w n-boyutlu bir vektör, b ise eșik değeridir. Buna ilave olarak $w$ ve $x$ 'in $1 / \mathrm{w}$ uzaklığındaki aşırı düzleme en yakın nokta olma koşulu getirilirse eşitlik Denklem 4'teki gibi yeniden düzenlenebilir;

$$
y_{i}\left(w^{T} \cdot x+b\right) \geq 1, \quad i=1,2, \ldots . N
$$

Aşırı düzlem ile en yakın noktaya uzaklığ en fazla olan düzlem (maksimum aralıktaki), en uygun ayrıştırıcı aşırı düzlem olarak adlandırılır. DVM'nin genelleme kabiliyeti bu ayrıștırıcı düzlemi maksimize etmekle sağlanır. Ekici ve arkadaşları Şekil 3'te en uygun aşırı düzlemi Vapnik'e göre göstermişlerdir [18,19]. Buradaki m maksimum aralık, $H$ ise en uygun ayrıștırıcı düzlemdir. 


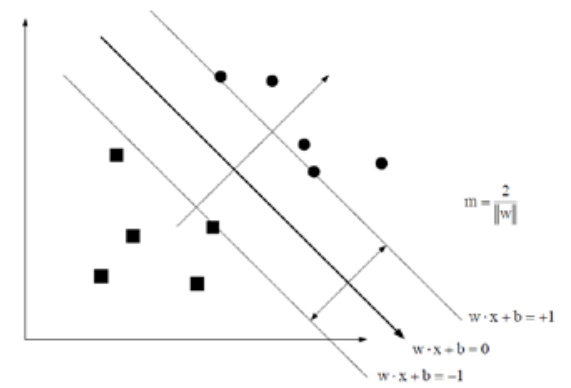

Şekil 3. En uygun ayrıștırıcı düzlem

\section{Bulgular}

$\mathrm{Bu}$ çalışmada, sinter makinesinin hız kontrolünü operatörden bağımsız otomatik olarak yapmak için bir örüntü tanıma sistemi geliştirilmiştir. 01.08.2014 ile 15.01.2015 tarihleri arasinda İsdemir sinter tesisinden toplanan, kamara sıcaklıkları, harman yüksekliği, emiş basınçları ve mevcut hız bilgilerinden oluşturulan 14040 kayıttan oluşan veri seti, \%70 oranında eğitim ve \% 30 oranında test verisi olmak üzere ikiye bölünmüştür. 9828 kayıttan oluşan eğitim verisi doğrusal ayırma sınıflandırıcısı, yapay sinir ağı ve destek vektör makineleri sınıflandırıcılarının eğitiminde

Sinıflandırıcıların kullanılmıştır. eğitiminde verisi ile sinıflandırıcıların performansları karşılaştırılmıştır.

$\mathrm{Bu}$ bölümde doğrusal ayırma sınıflandırıcısı, yapay sinir ağı ve destek vektör sınıflandırıcısının değişik parametrelerle alınan sonuçları verilecektir. Sınıflandırıcı performansları hata matrisinden elde edilen doğruluk, özgüllük ve kesinlik oranlarına göre değerlendirilmiştir. Üç sınıflı bir problem için hata matrisi Tablo 3'te gösterilmiştir.

Tablo 3'te DP DÜ, $\mathrm{DP}_{\mathrm{DE}}$ ve DPyü sırasıyla hız düşürme, hızı değiştirme ve hız yükselt sonuçlarının doğru tahmin edildiğini, diğer ifadeler ise sonuçların hatalı tahmin edildiğini göstermektedir.

Hız düşürme sınıfı için doğruluk, özgüllük ve kesinlik hesaplamalar Denklem 5, 6 ve 7'de verilmiştir. Doğruluk, özgüllük ve kesinlik değerleri diğer iki sınıf için de benzer şekilde elde edilmiştir.

Tablo 3. Hata matrisi.

\begin{tabular}{|c|c|c|c|c|}
\hline & \multicolumn{3}{|c|}{ Tahmini Değerler } & \multirow{2}{*}{$\begin{array}{l}\text { Gerçek Değer } \\
\text { Sayısı }\end{array}$} \\
\hline & $\begin{array}{l}\text { Hız Düșür } \\
\text { DÜ }\end{array}$ & \begin{tabular}{|c|} 
Hızı Değiştirme \\
DE \\
\end{tabular} & $\begin{array}{l}\text { Hız Yükselt } \\
\text { YÜ }\end{array}$ & \\
\hline $\begin{array}{l}\text { Hız Düşür } \\
\text { DÜ }\end{array}$ & $\begin{array}{l}\text { doğru pozitif } \\
\text { (düşür) } \\
\left(D_{\text {DÜ }}\right)\end{array}$ & $\begin{array}{c}\text { yanlış negatif } \\
\text { (düşür yerine } \\
\text { değiştirme) } \\
\left.\text { (YN } N_{\text {DÜDE }}\right)\end{array}$ & $\begin{array}{c}\text { yanlış negatif } \\
\text { (düşür yerine } \\
\text { yükselt) } \\
\text { (YN } \text { DÜYÜ })\end{array}$ & $\begin{array}{c}\mathrm{G}_{D U ̈}=\mathrm{DP}_{\text {DÜ }}+\mathrm{YN}_{\text {DÜD }} \\
\mathrm{E}+\mathrm{YN}_{\text {DÜYÜ }}\end{array}$ \\
\hline $\begin{array}{c}\text { Hızl } \\
\text { Değiștirme } \\
\text { DE }\end{array}$ & $\begin{array}{c}\text { yanlıș negatif } \\
\text { (değiştirme yerine } \\
\text { düşür) } \\
\text { (YNDEDÜ) }\end{array}$ & $\begin{array}{l}\text { doğru pozitif } \\
\text { (değiştirme) } \\
\left(\mathrm{DP}_{\mathrm{DE}}\right)\end{array}$ & $\begin{array}{c}\text { yanlış negatif } \\
\text { (değiştirme } \\
\text { yerine yükselt) } \\
\text { (YN DEYü) }\end{array}$ & $\begin{array}{c}\mathrm{G}_{\mathrm{DE}}=\mathrm{YN}_{\mathrm{DEDU}}+\mathrm{DP}_{\mathrm{D}} \\
\mathrm{E}+\mathrm{YN}_{\mathrm{DEYU}}\end{array}$ \\
\hline $\begin{array}{l}\text { Hız Yükselt } \\
\text { YÜ }\end{array}$ & $\begin{array}{c}\text { yanlış negatif } \\
\text { (yükselt yerine } \\
\text { düşür) } \\
\text { (YNYüDÜ) }\end{array}$ & $\begin{array}{l}\text { yanlış negatif } \\
\text { (yükselt yerine } \\
\text { değiştirme) } \\
\text { (YNYüDE) }\end{array}$ & $\begin{array}{l}\text { doğru pozitif } \\
\text { (yükselt) } \\
\text { (DPYü) }\end{array}$ & $\begin{array}{c}\text { GYÜ=YNYÜDÜ } \\
+ \text { YNYÜDE }^{\text {DPYÜ }}\end{array}$ \\
\hline $\begin{array}{c}\text { Toplam } \\
\text { Tahmin Sayıs } \\
\end{array}$ & $\begin{aligned} \mathrm{T}_{\mathrm{DÜ}}= & \mathrm{DP}_{\mathrm{DU}}+\mathrm{YN}_{\mathrm{DEDÜ}} \\
& +\mathrm{YN}_{\mathrm{YU}} \mathrm{BÜU}\end{aligned}$ & $\begin{aligned} \mathrm{T}_{\mathrm{DE}}= & =\mathrm{YN}_{\mathrm{DÜDE}}+\mathrm{DP}_{\mathrm{DE}} \\
& +\mathrm{YN}_{\mathrm{YÜDE}}\end{aligned}$ & $\begin{array}{c}T_{Y U ̈ U}=Y_{\text {DUÜYÜ }}+Y N \\
\text { DEYÜ }+D_{Y U ̈}\end{array}$ & \\
\hline
\end{tabular}


${\operatorname{Doğ} r u l u k_{D U ̈}}=\frac{D P_{D \ddot{U}}}{G_{D U ̈}}$

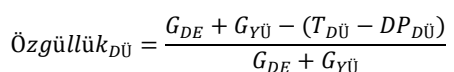

$\operatorname{Kesinlik}_{D \ddot{U}}=\frac{D P_{D U ̈}}{T_{D U ̈}}$

Tablo 3'te verilen hata matrisine dayanılarak yapılan değerlendirmeye göre, tek temel parametresi ile kullanılan doğrusal ayırma sınıflandırıcısında, sinter prosesinde giriş çıkış ilişkilerinin doğrusal olmamasından dolayı doğruluk oranları \%72 seviyesinde kalmıștır.

$\mathrm{Bu}$ çalıșmada ileri beslemeli çok katmanlı yapay sinir ağı kullanılmış, farklı gizli katman, nöron sayıları ve aktivasyon fonksiyonları ile deneyler yapılmıştır. Bu deneylerden elde edilen sonuçlar Tablo 4' te gösterilmiştir.

Tablo 4. İleri beslemeli yapay sinir ağı ile elde edilen sonuçlar

\begin{tabular}{cc}
\hline Ağ Parametreleri & Doğruluk \\
Gizli Katman/Nöron Sayısı/ & Oranı \\
Aktivasyon Fonksiyonu & {$[\%]$} \\
\hline 1 Gizli Katman/5 Nöron/Logsig F & 78,18 \\
1 Gizli Katman/15 Nöron/Logsig F & 79,46 \\
1 Gizli Katman/5 Nöron/Tansig F & 77,35 \\
1 Gizli Katman/15 Nöron/Tansig F & 77,37 \\
2 Gizli Katman/5-5 Nöron/Logsig F & 80,81 \\
2 Gizli Katman/7-10 Nöron/Logsig F & 79,20 \\
2 Gizli Katman/5-5 Nöron/Tansig F & 80,05 \\
2 Gizli Katman/7-10 Nöron/Tansig F & 80,10 \\
3 Gizli Katman/5-5-5 Nöron/Logsig F & 82,50 \\
3 Gizli Katman/5-10-15 Nöron/Logsig F & 82,19 \\
3 Gizli Katman/5-5-5 Nöron/Tansig F & 81,64 \\
3 Gizli Katman/5-10-15 Nöron/Tansig F & 82,54 \\
\hline
\end{tabular}

Tablo 4' te yapay sinir ağı ile yapılan deneylere ait sonuçlar verilmektedir. En iyi sonuç, üç gizli katmandan oluşan ve ilk gizli katmanda beş nöron, ikinci gizli katmanda on nöron ve üçüncü gizli katmanda on beș nöron kullanılan YSA ile elde edilmiştir.

Destek vektör sınıflandırıcısında ilk adım olarak 6 Mart 2015 tarihinden itibaren alınan 1000 adet veri ile polinomsal, homojen, eksponansiyel, radyal gibi çekirdek fonksiyon için tüm yakınlık tipi parametreleri ve derece seçenekleri ile en başarılı sonucun hangisi olduğu belirlenmiş ve sonuçlar Tablo 5' te gösterilmiştir. Daha sonra en iyi sonucun alındığı üç tip ve derece için eldeki eğitim ve test verileri değerlendirilerek alınan sonuçlar Tablo 6' da gösterilmiştir.

Tablo 5. DVM ile en iyi bașarıyı yakalamak için yapılan tüm yakınlık ve derecelere göre alınan sonuclar

\begin{tabular}{cccc}
\hline Yakınlık & Derece & mce & Başarı [\%] \\
\hline polinomsal & 2 & 0,183 & 81,71 \\
polinomsal & 3 & 0,191 & 80,94 \\
polinomsal & 4 & 0,237 & 76,26 \\
homojen & 1 & 0,234 & 76,59 \\
homojen & 3 & 0,197 & 80,27 \\
homojen & 4 & 0,247 & 75,26 \\
uzaklık & 2 & 0,251 & 74,92 \\
uzaklık & 4 & 0,177 & 82,28 \\
uzaklık & 5 & 0,297 & 70,24 \\
eksponansiyel & 5 & 0,237 & 76,26 \\
radyal & 5 & 0,237 & 76,26 \\
sigmoid & 3 & 0,345 & 65,22 \\
minkowski & 3 & 0,345 & 65,22 \\
city-block & - & 0,345 & 65,22 \\
cosine & - & 0,345 & 65,22 \\
\hline
\end{tabular}

Destek vektör makinelerinin en yüksek doğruluğu veren polinomsal, homojen ve uzaklık (distance) yakınlık tiplerine ( $\mathrm{p}-2, \mathrm{~h}-3, \mathrm{u}-4)$ aynı bağımsız test verileri uygulanmış ve buna göre destek vektör sınıflandırıcısının en iyi üç yakınlık tipine ve parametresine göre elde edilen sonuçlar Tablo 6' da gösterilmiştir.

Tablo 6. DVM polinomsal, homojen ve uzaklık tiplerinin en iyi yakınlık derecelerinden alınan sonuçlar

\begin{tabular}{cccc}
\hline Yakınlık Tipi & Derece & mce & Bașarı [\%] \\
\hline polinomsal & 2 & 0,200 & 79,96 \\
homojen & 3 & 0,217 & 78,30 \\
uzaklık & 4 & 0,202 & 79,75 \\
\hline
\end{tabular}

Eğitim verisi içermeyen aynı bağımsız test verisi üzerinde yapılan denemeler sonucunda en yüksek performansı gösteren sinıflandirıciların performansları Tablo 7' de karşılaştırılmıştır. 
Tablo 7. Üç farklı sinıflandırıcıdan alınan sonuçların karşılaștırılması

\begin{tabular}{cc}
\hline Sınıflandırıcı & Doğruluk [\%] \\
\hline Doğrusal Ayırma Sınıflandırıcısı & 72,3 \\
Yapay Sinir Ağı & 82,54 \\
Destek Vektör Makinesi & 79,96 \\
\hline
\end{tabular}

Tablo 7'de doğrusal ayırma sinıflandırıcısının varsayılan parametreleri ile elde edilen en başarılı sonucu gösterilmiştir. Yapay sinir ağl için değişik katman, nöron ve aktivasyon fonksiyonları içinde en başarılı sonucu veren üç katmanlı, beş, on, on beş nöron sayll ve sigmoid aktivasyon fonksiyonlu olan yapay sinir ağının doğruluk değeri gösterilmiştir. Destek vektör sınıflandırıcısının da tüm yakınlık tipi ve dereceleri denendikten sonra en iyi sonucu veren polinomsal tip, ikinci derece sinıflandırıcısının değeri gösterilmiştir.

\subsection{Uygulama}

$\mathrm{Bu}$ çalışmada sözü edilen sıcaklık, basınç ve harman seviyesi verilerine göre makine hızını otomatik ayarlayan bir model yazılımı geliștirilerek 2014 yılı Temmuz ayında İsdemir sinter fabrikalarında kullanılmaya başlanmıştır. Modelin kullanılmasından sonra 2015 yılı Temmuz ayında yapılan değerlendirmeye göre sinter makine verimi $\% 10$ oranında artırılmıştır. Geliştirilen model ile sinter makinesi aynı yüksek verimle çalıştırılmaya devam edilmektedir.

\section{Tartışma ve Sonuç}

$\mathrm{Bu}$ çalışmada İskenderun Demir Çelik A.Ş. (İSDEMIR) sinter tesislerinin en modern makinesi olan yeni sinter makinesinin hiz tayininin operatör kontrolünden alınarak otomatik kullanılmasını sağlayacak örüntü tanıma sistemi geliștirilmiștir.

Sinter makinesi hızını belirlemek için sıcaklık bilgilerinden elde edilen BRP noktası, harman seviyesi, basınç ve mevcut hız bilgilerinden oluşan bir veri seti oluşturulmuştur. Yapılan işlemin sonucu ise makine hızının artırılması, düşürülmesi ya da aynı bırakılması olmuştur.

Sınıflandırma için doğrusal ayırma sınıflandırıcısı, yapay sinir ağları ve destek vektör makineleri kullanılmıștır. Doğrusal ayırma sinıflandırıcısının işlem hızı çok yüksektir ve çok kısa sürede sonuç vermektedir. Fakat özellikle sıcaklık verilerinin doğrusal olmamasından dolayı bu sınıflandırıcının doğruluk oranı \% 72 seviyelerinde kalmıştır. Yapay sinir ağl, farklı katman, nöron sayıları ve aktivasyon fonksiyonları ile denendikten sonra en iyi sonucun alındığı üç gizli katman, beş, on ve on beş nöronlu ve sigmoid fonksiyonlu ağda \% 83 doğruluk oranına ulaşılmıştır. Destek vektör makineleri kullanıldığında en iyi sonuçlara polinomsal, homojen ve uzaklık (distance) çekirdek fonksiyonları ile ulaşılmıştır. $\mathrm{Bu}$ üç farklı çekirdek fonksiyonunda da yaklaşı aynı doğruluk oranına ulaşılmıştır. \%80 oranıyla yapay sinir ağlarına çok yakın bir sonuç elde edilmiştir.

Sinter prosesinin doğrusal olmayan bir yapıda olması, birden çok parametrenin makine hızını etkilemesi ve bu parametreler arasında zaman farkları olması, çalışılan yöntemlerin doğruluk oranına etki etmiștir. Makine hızı tahmininde daha yüksek doğrulukta sonuçlara ulaşmak için üretimde karşılaşılan istisnai durumların elimine edilmesi, kısa süreli duruşların önüne geçilmesi, sıcaklık, harman seviyesi ve nem gibi parametrelerdeki anlık aşırı dalgalanmaların giderilmesi gerekir. $\mathrm{Bu}$ tür olumsuzlukların önüne geçmek için sinter makinelerinde malzeme bunkeri kontrolü, geri dönen sinter tozu kontrolü ve nem kontrolü gibi uygulamalar yapılmaktadır. Dolayısıyla sadece makine hızı kontrolü yerine 
yukarıda sayılan tüm kontrollerin birlikte çalıştırılması ile çok daha yüksek doğruluklara ulaşılması beklenmektedir.

Sinter makinesi hız tahmininin otomatik olarak yapılması ile makine hızı kontrolünde operatör müdahalesinin ortadan kaldırılmasl, operatör ve vardiyadan bağımsız olarak her zaman aynı kararlılıkla makinenin yönetilmesi ve bu sayede makinenin daha verimli çalıştırılması gerçekleşecektir.

\section{Kaynakça}

[1] Xiang, J., Wu, M., Duan, P., Cao, W., He, Y., 2008. Coordinating fuzzy control of the sintering process. Proceedings of the 17th World Congress the International Federation of Automatic Control, Seoul, July 6-11, Korea, 7717-7722.

[2] Wu, M., Duan, P., Cao, W., She, J., Xiang, J., 2012. An intelligent control system based on prediction of the burn through point for the sintering process of an iron and steel plant. Elsevier, Cilt. 39, s. 5971-5981. DOI:10.101/j.eswa.2011.11.118

[3] Song, G., Wang, A., Zhang, Y., 2013. The combination prediction of BTP in sintering process based on Bayesian framework and LS-SVM. Telkomnika, Cilt. 11, s. 4616-4626.

[4] Wang, B., Fang, Y., Sheng, J., Gui, W., Sun, Y., 2009. BTP Prediction Model Based on ANN and Regression Analysis. Second International Workshop on Knowledge Discovery and Data Mining, s.108-111. DOI: 10.1109 / WKDD.2009.179

[5] Ai-min, W., Qiang, S., 2007. Prediction of $\mathrm{R}$ in Sinter Process based on Grey Neural Network Algebra. Eighth ACIS International Conference on Software Engineering, Artificial Intelligence, Networking, and Parallel /
Distributed Computing, s.248-252. DOI:10.1109/SNPD.2007.65

[6] Duda, R. O., Hart, P. E., Stork, D. G. 2001, Pattern Classification. Second edition. John Wiley, United States of America, 654s.

[7] Erkınay, Z.M. 2012. Dismorfik hastalıkların sinyal işleme yöntemleri kullanılarak sinıflandırılması. Ankara Üniversitesi Fen Bilimleri Enstitüsü, Doktora Tezi, 99 s, Ankara.

[8] Toylan H. 2012. Yapay zeka örüntü tanıma algoritması kullanarak sinıflandirma otomasyonunun tasarımı. Trakya Üniversitesi Fen Bilimleri Enstitüsü, Doktora Tezi, 124 s, Edirne.

[9] Asht, S., Dass, R., 2012. Pattern Recognition Techniques: A Review. International Journal of Computer Science and Telecommunications, Cilt. 3, s. 25-29.

[10] Sucharta, V., Jyothi, S. 2013. A Survey on Various Pattern Recognition Methods for the Identification of a Different Types of Images. Publications of Problems \& Application in Engineering Research - Paper, Cilt. 4, s. 178-181.

[11] Denoeux, T., Masson, M., Dubuisson, B. Advanced Pattern Recognition Techniques for System Monitoring and Diagnosis: A survey. France

[12] Beşkardeş, A., Özdemir Erkınay, M., Yıldırım, S. 2015. Sinter makinesinde ısıl kontrole bağlı hız kontrolü, SİU-2015: Sinyal İşleme ve İletişim Uygulamaları Kurultayı Malatya, 1154-1158.

[13] Junoh, A.K., Mansor, M.N., 2012. Safety System Based on Linear Discriminant Analysis. International Symposium on Instrumentation \& Measurement, Sensor Network and Automation (IMSNA), s. 32-34. 
[14] Alpaydın, E. 2013. Yapay öğrenme. Boğaziçi Üniversitesi Yayınevi, İstanbul, $496 \mathrm{~s}$.

[15] Elmas, C.. 2010. Yapay zeka uygulamaları. Seçkin Yayıncılık, Ankara, $424 \mathrm{~s}$.

[16] Baddari, K., Djarfour, N., Aifa, T., Ferahtia, J., 2010. Acoustic impedance inversion by feedback artificial neural network. Elsevier, Cilt. 71, s. 106-111. DOI: 10.1016/j.petrol.2009.09.012

[17] Jiang, Z., Fu, H., Li, L. 2005. Support vector machine for mechanical faults classification: Journal of Zhejiang University Science, Cilt.6, s. 433-439. DOI: 10.1007/BF02839412

[18] Ekici, S., Yıldırım, S. ve Poyraz, M. 2008. Mesafe koruma için bir örüntü tanıma uygulaması: Gazi Üniversitesi Mühendislik Mimarlık Fakültesi Dergisi, Cilt. 24, s. 51-61.

[19] Vapnik, V.N. 1998. Statistical Learning Theory. (S. Haykin, Editör). In: John Wiley \& Sons, Inc United States of America. 